\title{
The Role of Free Radicals in Hemolytic Toxicity Induced by Atmospheric-Pressure Plasma Jet
}

\author{
Ku Youn Baik, ${ }^{1}$ Yoon Ho Huh, ${ }^{1}$ Yong Hee Kim, ${ }^{1}$ Jeongho Kim, ${ }^{2}$ Min Su Kim, ${ }^{3}$ \\ Hun-Kuk Park, ${ }^{2}$ Eun Ha Choi, ${ }^{1}$ and Byoungchoo Park ${ }^{1}$ \\ ${ }^{1}$ Department of Electrical and Biological Physics, Kwangwoon University, Seoul 01897, Republic of Korea \\ ${ }^{2}$ Department of Biomedical Engineering, College of Medicine, Kyung Hee University, Seoul 02447, Republic of Korea \\ ${ }^{3}$ College of Veterinary Medicine, Chonbuk National University, 79 Gobong-Ro, Iksan, Jeonbuk 54596, Republic of Korea
}

Correspondence should be addressed to Eun Ha Choi; ehchoi@kw.ac.kr and Byoungchoo Park; bcpark@kw.ac.kr

Received 20 January 2017; Revised 23 March 2017; Accepted 5 April 2017; Published 14 June 2017

Academic Editor: Tiziana Persichini

Copyright ( $) 2017 \mathrm{Ku}$ Youn Baik et al. This is an open access article distributed under the Creative Commons Attribution License, which permits unrestricted use, distribution, and reproduction in any medium, provided the original work is properly cited.

\begin{abstract}
Atmospheric-pressure plasma (APP) has received attention due to its generation of various kinds of reactive oxygen/nitrogen species (ROS/RNS). The controllability, as well as the complexity, is one of the strong points of APP in various applications. For biological applications of this novel method, the cytotoxicity should be estimated at various levels. Herein, we suggest red blood cell (RBC) as a good cell model that is simpler than nucleated cells but much more complex than other lipid model systems. Air and $\mathrm{N}_{2}$ gases were compared to verify the main ROS/RNS in cytotoxicity, and microscopic and spectroscopic analyses were performed to estimate the damages induced on RBCs. The results shown here will provide basic information on APP-induced cytotoxicity at cellular and molecular levels.
\end{abstract}

\section{Introduction}

Atmospheric-pressure plasma (APP) has received attention as a powerful tool for biomedical applications, such as wound healing and cancer therapeutics [1-4]. APP can generate various kinds of reactive oxygen/nitrogen species (ROS/RNS) at one time, such as $\mathrm{OH} \bullet, \mathrm{HO}_{2}, \mathrm{H}_{2} \mathrm{O}_{2}, \mathrm{O}_{3}, \mathrm{NO}$, and $\mathrm{NO}_{\mathrm{x}}^{-}$, which are controllable by the plasma conditions and environmental conditions [5-7]. APP can induce various biological responses according to the target cells. For example, immune cells produced cytokines [8], and melanocytes produced melanin in response to APP stimuli, resulting in different biological activities [9]. As another example, APP can preferentially kill some cancer cells, when normal cells overcame the same stress [4]. These active responses of cells to the same molecular stimulus make it difficult to standardize APP. In order to make APP successful in medical applications, exact understanding of the primary events as well as the given cytotoxicity should be obtained, before applying APP in each disease.

Red blood cells (RBCs) have been used as a model to investigate oxidative damage in biomembranes. Mammalian
RBCs do not have nuclei, ribosomes, and mitochondria, so they do not have protein synthesis systems and mitochondria-based oxidative reactions [10]. Therefore, the response of RBCs to oxidative stress is rather passive and mainly restricted to the membrane. Their main responses are lipid peroxidation, changes in cellular morphology, protein cross-linking, and consequently hemolysis [11, 12]. Another importance of RBCs is their ubiquitous presence in tissues and also their circulation throughout the whole body. APP treatment cannot avoid influencing RBCs during in vivo therapy. In addition, despite their lack of mitochondria, ROS are continuously produced in the RBCs due to the high $\mathrm{O}_{2}$ tension in arterial blood and their abundant heme iron content. RBCs are known to regulate vascular oxidative stress through Fenton reaction or NO scavenging by heme irons. Hence, RBC is one of the simplest model systems for the study of toxicity in vitro and one of the important variables for the elucidation of the redox mechanism of APP action in vivo.

Herein, we demonstrate the differential responses of RBCs to pure $\mathrm{N}_{2}$ and air gas APP in hemolytic toxicity 


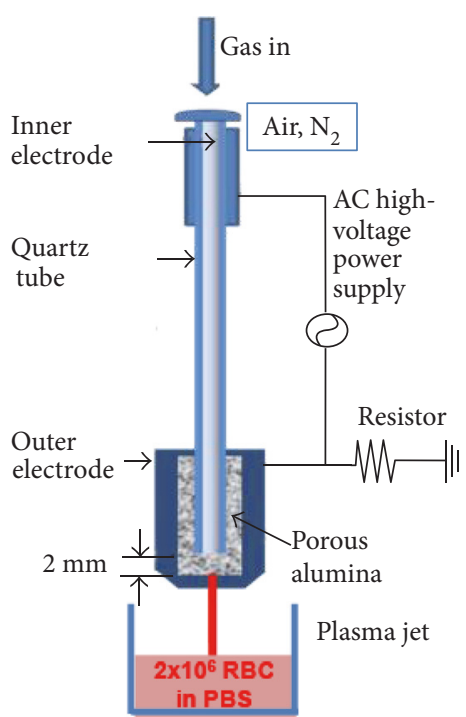

(a)

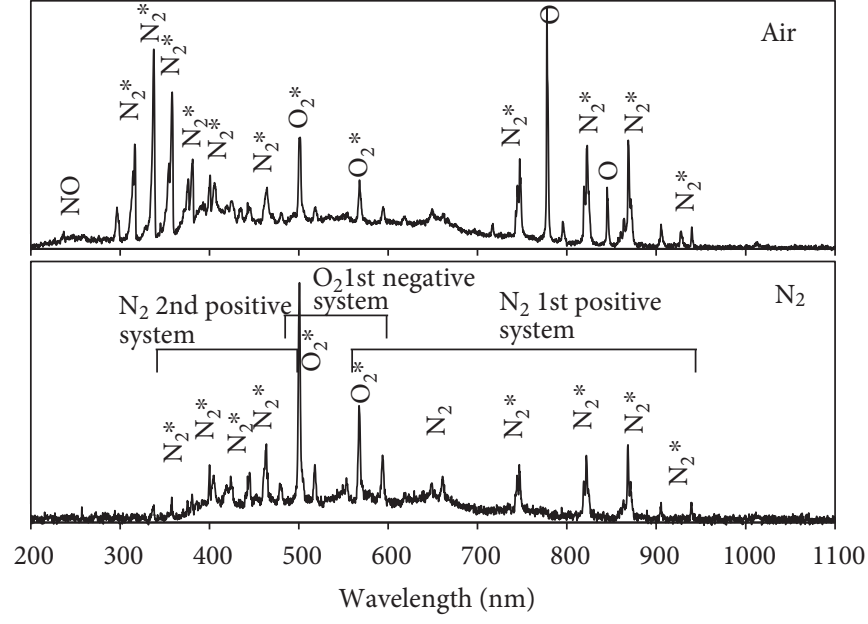

(b)
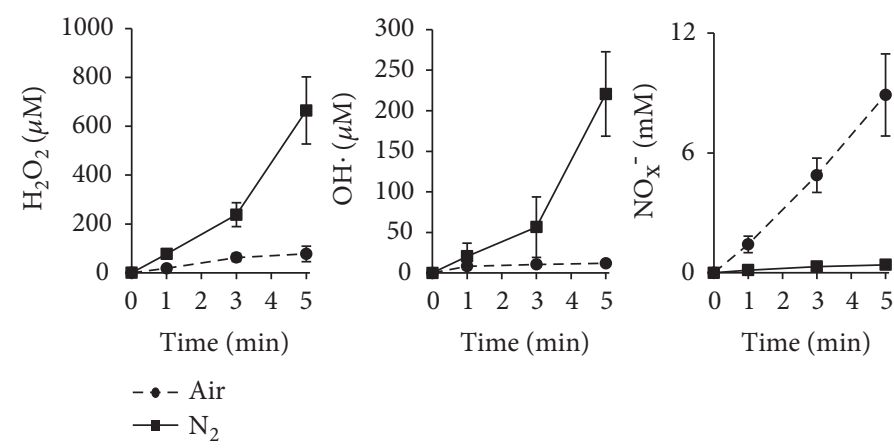

(c)

FIGURE 1: Schematics of nonthermal atmospheric-pressure plasma jet (APPJ) with dielectric porous ceramic and the comparison of the plasma composition between $\mathrm{N}_{2}$ and air-feeding gases. (a) A schematic of our experimental system. (b) Optical emission spectroscopy of the plasma plume. (c) Colorimetric analysis of $\mathrm{H}_{2} \mathrm{O}_{2}, \mathrm{OH}$, and $\mathrm{NO}$ in plasma-treated PBS solution.

through membrane damages. In previous reports, we showed that the $\mathrm{N}_{2}$ and air gas APP caused differences in the plasma compositions, liquid interactions, and bactericidal effects. Air plasma generated greater amounts of $\mathrm{NO}_{2}^{-}$and $\mathrm{NO}_{3}^{-}$, while $\mathrm{N}_{2}$ plasma generated more $\mathrm{NH}_{4}^{+}$, and showed higher cytotoxicity [6]. In this study, the changes in the RBC morphology, rheological properties, hemolysis, lipid NMR spectroscopy, Raman spectroscopy, and absorption spectroscopy to APP have been examined. The results shown here will provide basic information on APP-induced cytotoxicity in cell and molecular levels.

\section{Materials and Methods}

2.1. The Atmospheric-Pressure Plasma Device and Its Characteristics. Figure 1(a) shows our nonthermal plasma jet system at atmospheric pressure, consisting mainly of a high-voltage power supply, electrodes, and dielectrics. Porous alumina, which has a porosity of $30 \%$ and a pore diameter of $100 \mu \mathrm{m}$, is used as a dielectric medium between stainless steel electrodes to induce microdischarges and reduces the gas temperature. A more detailed description can be found in previous reports $[6,13]$. Voltage of $80 \mathrm{~V}$ at $60 \mathrm{~Hz}$ was input into a commercial transformer, resulting in an output frequency of approximately $10 \mathrm{kHz}$ and an output voltage of about $1 \mathrm{kV}$. The output voltage and current waveforms have a sawtooth profile, with an average power of $3 \mathrm{~W}$. The air and $\mathrm{N}_{2}$ gas (99.9\%) flow rate was $1.0 \mathrm{l} / \mathrm{min}$, and a plasma jet with a plume was ejected into the open air through a $1 \mathrm{~mm}$ hole. Spectroscopic measurements were performed with a charge-coupled device (CCD) spectrometer (HR4000, Ocean Optics) and optical fiber (QP400-2-SR) with a diameter of $400 \mu \mathrm{m}$. The signal was accumulated for five minutes.

2.2. Measurement of $\mathrm{H}_{2} \mathrm{O}_{2}, \mathrm{OH}$, and $\mathrm{NO}$ in PBS Solution. Immediately after treating phosphate-buffered saline (PBS: LB001-02, Welgene) with atmospheric-pressure plasma jet (APPJ), the concentrations of $\mathrm{H}_{2} \mathrm{O}_{2}, \mathrm{OH} \bullet$, and $\mathrm{NO}_{\mathrm{x}}^{-}\left(\mathrm{NO}_{2}^{-}\right.$ and $\mathrm{NO}_{3}^{-}$); temperature; and $\mathrm{pH}$ were measured. The concentration of $\mathrm{H}_{2} \mathrm{O}_{2}$ was determined with Amplex Red reagents (A22188, Molecular Probes), following the manufacturer's 
protocol. $20 \mathrm{mM}$ terephthalic acid (TA, 185361, Aldrich) solution was directly exposed to APPJ, and the fluorescence intensity was quickly measured. The concentration of $\mathrm{NO}_{\mathrm{x}}^{-}$ was measured with a nitric oxide colorimetric assay kit (K262-200, BioVision), following the manufacturer's protocol. The fluorescence and color changes were measured by a plate reader (Synergy HT, BioTek). The standard curve of $\mathrm{OH}$ radical was made with the solutions of different ratios of $20 \mathrm{mM}$ hydroxyl-terephthalic acid (752525, Aldrich) in $20 \mathrm{mM}$ TA solution. Considering TA binding affinity for $\mathrm{OH}$ was $35 \%$ with $\mathrm{O}_{2}$, the measured $\mathrm{OH}$ radical concentration should be higher. $\mathrm{pH}$ was measured using a $\mathrm{pH}$ meter (Eutech Instruments, Singapore). pH of PBS was not changed by 5 minutes of APPJ treatment (data not shown). The temperature of the solutions increased with APPJ exposure. It reached around $35^{\circ} \mathrm{C}$ when room temperature was $25^{\circ} \mathrm{C}$.

\subsection{Preparation of $R B C$ and Lipid Extraction from Canine} Whole Blood. The blood was collected from Beagles and stored in a vacuum bag with anticoagulant CPDA-1 at $4^{\circ} \mathrm{C}$ before use. The RBCs were purified from the whole blood using Histopaque ${ }^{\circledR}-1077$ (10771, Sigma). The serum was washed out with $1 \times$ PBS $(\mathrm{pH} 7.0)$ by centrifugation at $1500 \mathrm{rpm}$ for $10 \mathrm{~min}$. Washing with PBS was repeated for 5 times, and $1 \times 10^{8}$ cells $/ \mathrm{ml}$ in PBS was prepared as a stock solution. For APPJ treatment, $1 \mathrm{ml}$ of $2 \%$ of stock in PBS solution was put in a 24 -well plate placed under $3 \mathrm{~mm}$ from the outer electrode.

For hemolysis test, the cell suspension was centrifuged at $5000 \mathrm{rpm}$ for $10 \mathrm{~min}$. The absorbance of the supernatant was measured by a plate reader (Synergy HT, BioTek) at $415 \mathrm{~nm}$, because hemoglobin has maximum absorbance there and absorbance between 500 and $700 \mathrm{~nm}$ was changed by APPJ treatment. The absorbance of PBS only and RBC in $10 \%$ Triton X-100 solution was considered $0 \%$ and $100 \%$ hemolysis, respectively.

For lipid extraction, 4 volumes of $0.2 \%$ ice-cold acetic acid were added and vigorously vortexed. The homogenate was incubated in ice for $5 \mathrm{~min}$, with occasional shaking, then centrifuged at $2500 \mathrm{rpm}$ for $10 \mathrm{~min}$ at $4^{\circ} \mathrm{C}$, and the supernatant containing intracellular components was removed. New ice-cold $0.2 \%$ acetic acid solution was added and centrifuged. This step was repeated more than 5 times to fully remove the intracellular contents. 10 volumes of methanolchloroform $(2: 1, \mathrm{vol} / \mathrm{vol})$ solution were added to the RBC ghost suspension, and the mixture was vortexed for 5 minutes. $0.5 \mathrm{M} \mathrm{KCl}$ in $50 \%$ methanol was added, vortexed, and centrifuged. The upper layer was removed, and the step was repeated two more times. The lower layer was dried and resolved in proper solvents for further analysis [14].

2.4. Measurement of RBC Deformability. We used RheoscanAnD300 (RheoMeditech, Seoul, Korea) to measure the deformability of the RBCs treated with air or $\mathrm{N}_{2}$ plasma jet over different exposure times, that is, 1,3 , and $5 \mathrm{~min}$. This ektacytometer uses a laser diffraction technique with microfluidic rheometry and incorporates a disposable microchip [15]. After plasma exposure, the canine RBC suspension was centrifuged at $1700 \mathrm{~g}$ for $5 \mathrm{~min}$ and washed two times with PBS. Six microliters of the packed RBCs were then mixed with $0.5 \mathrm{ml}$ of polyvinylpyrrolidone (PVP) solution with a viscosity of 30 centipoise at $37^{\circ} \mathrm{C}$. The $\mathrm{RBC}$ suspension was then injected into a microchip (K-02; RheoMeditech). Test samples flow through a microchannel and experience vacuum-driven shearing. The deformation of the RBC is analyzed by obtaining diffraction images over a range of shear stresses. The captured images of the RBCs were analyzed to calculate the elongation index (EI), defined as $(L-W) /(L+W)$, where $W$ and $L$ are the maximum and minimum axes of the ellipse, respectively.

\subsection{Raman Spectroscopy, NMR Spectroscopy, and Absorption} Spectroscopy. The chemical changes of RBC were analyzed using optical absorption spectroscopy, Raman spectroscopy, and NMR spectroscopy. For the optical spectroscopy, RBC suspension was used directly, and the absorption was read in the plate reader (Synergy HT, BioTek) from 300 to $700 \mathrm{~nm}$ at $10 \mathrm{~nm}$ intervals. For Raman spectroscopy, the slide glass was cleaned with piranha solution $\left(\mathrm{H}_{2} \mathrm{SO}_{4}: \mathrm{H}_{2} \mathrm{O}_{2}=3: 1\right)$ and coated with gold of $20 \mathrm{~nm}$ thickness (Ti 100/Au $200 \AA$ ) by thermal evaporation. RBC and lipid extracted from RBC was dropped onto the gold surface and dried in air. The chemical bonding properties were examined by Raman spectroscopy (Alpha300, WITec) with a $\times 50$ object lens and an acquisition time of $10 \mathrm{~s}$. Three different wavelengths including $488 \mathrm{~nm}, 532 \mathrm{~nm}$, and $633 \mathrm{~nm}$ were used with the laser power of $1 \mathrm{~mW}$. For the ${ }^{1} \mathrm{H}$ NMR measurement, the liquid extracted from $\mathrm{RBC}$ was recovered with $\mathrm{CDCl}_{3}$, and the ${ }^{1} \mathrm{H}$ NMR spectra were recorded by Bruker AVANCE $600 \mathrm{MHz}$ (14.1 T) spectrometry using a $5 \mathrm{~mm}$ TXI cryoprobe. The NMR spectra are assigned with reference to the NMR lipid database. Antioxidants used for optical spectroscopy were purchased from companies as follows: catalase (CAT; C3556, Sigma), superoxide dismutase (SOD; S9636, Sigma), carboxy-2-phenyl-4,4,5,5-tetramethylimidazoline-1-oxyl 3oxide (cPTIO, 81540, Cayman), and terephthalic acid (TA; 185361, Aldrich). The units of the enzyme activities for CAT and SOD were calculated according to the properties supported by the company. One unit of CAT can decompose $1.0 \mu \mathrm{M}$ of $\mathrm{H}_{2} \mathrm{O}_{2}$ per minute at $\mathrm{pH} 7.0$ at $25^{\circ} \mathrm{C}$. One unit of SOD can inhibit the rate of reduction of cytochrome $\mathrm{c}$ by $50 \%$ in a coupled system using xanthine and xanthine oxidase.

\section{Results and Discussion}

3.1. Reactive Species Generated from APPJ according to Feeding Gases. In our experimental condition, air and $\mathrm{N}_{2}$ APPJ generated various types of ROS/RNS in gas states. In optical emission spectroscopy, spectra related to $\mathrm{N}_{2}$-excited molecules were dominant in both the air and $\mathrm{N}_{2}$ APPJ (Figure 1(b)). The $\mathrm{N}_{2}$ second-positive system $\left(C^{3} \Pi_{\mathrm{u}}-\mathrm{B}^{3} \Pi_{\mathrm{g}}\right)$ was typically accompanied by the $\mathrm{N}_{2}$ first-positive system $\left(B^{3} \Pi_{g}-A^{3} \Pi_{u}^{+}\right)$, which indicated the formation of $N_{2} A^{3} \Sigma_{u}^{+}$ long-lived metastable states as reservoirs of energypromoting plasma chemical reactions. However, atomic $\mathrm{O}$ spectra dissociated by higher energy transfers were observed only in air plasma, which was consistent with previous 

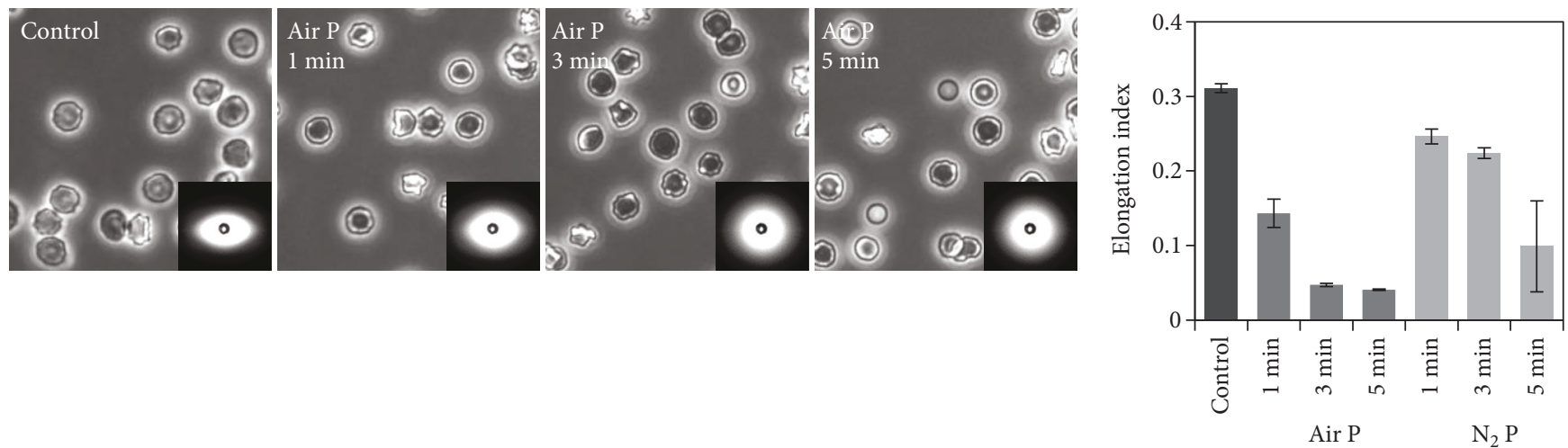

(a)

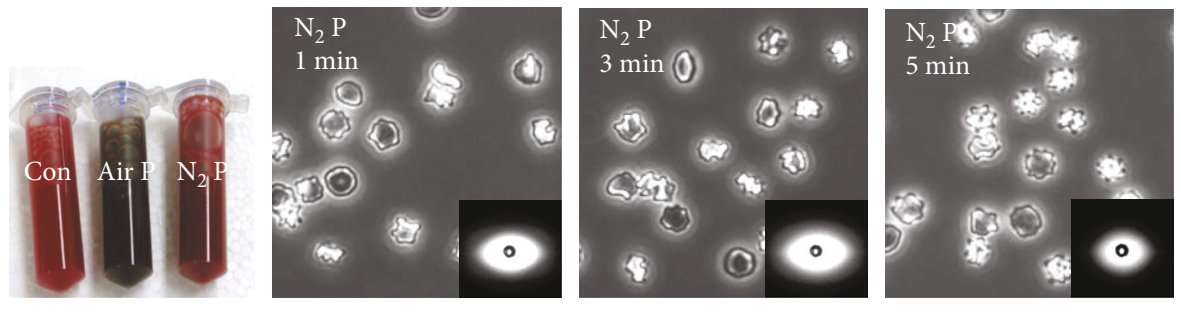

(c)

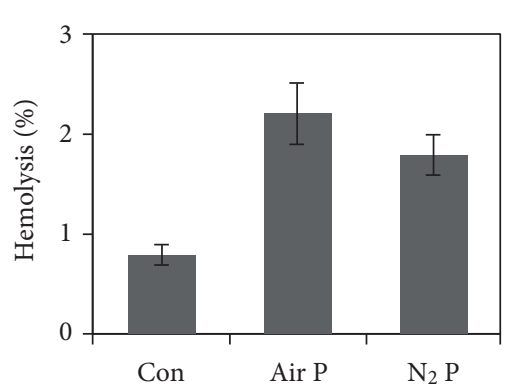

(d)

Figure 2: Morphological changes of RBCs by air and $\mathrm{N}_{2}$ APPJ treatment, and their hemolytic phenomena. (a) Optical microscopic images with small inserted images showing deformability under shear force. (b) Measurement of deformability. (c) Photograph of RBC solutions by air and $\mathrm{N}_{2}$ plasma treatment for $5 \mathrm{~min}$. (d) Measurement of hemolysis of RBC solutions by air and $\mathrm{N}_{2}$ plasma treatment for 1 min.

reports showing a higher gas temperature in $\mathrm{O}_{2}$ plasma than in $\mathrm{N}_{2}$ plasma. The number of electrons was decreased by attachment during the formation of negative $\mathrm{O}^{-}$and $\mathrm{O}_{2}^{-}$ions, and the lifetimes of active molecules were also found to be shorter in air plasma, due to collisional quenching by oxygen.

To understand the biological effects of APPJ in solutions, $\mathrm{H}_{2} \mathrm{O}_{2}, \mathrm{OH}$, and $\mathrm{NO}_{\mathrm{x}}^{-}$were quantitatively analyzed (Figure 1(c)). All the values increased with the increase of APPJ treatment time. The amounts of $\mathrm{H}_{2} \mathrm{O}_{2}$ and $\mathrm{OH}$. were measured much higher in the solution treated with $\mathrm{N}_{2}$ APPJ, while the amount of $\mathrm{NO}_{\mathrm{x}}^{-}$was measured much higher in the solution treated with air APPJ. The higher amount of $\mathrm{H}_{2} \mathrm{O}_{2}$ and $\mathrm{OH}$. may be ascribed to higher electron density in $\mathrm{N}_{2}$ APPJ, since the electrons in the air plasma plume easily attach to oxygen species. Electrons hydrolyze water molecules, forming various submolecular species out of water molecules, such as hydrogen atoms and hydroxyl radicals. The higher amount of $\mathrm{NO}_{\mathrm{x}}^{-}$species may be ascribed to higher atomic $\mathrm{O}$ and NO molecules in air APPJ. These characteristics may be connected to different chemical reactions caused by air and $\mathrm{N}_{2}$ plasma.

3.2. Morphological Changes and Hemolytic Toxicity of RBCs. In order to investigate the effects of respective air and $\mathrm{N}_{2}$ APPJ treatment on mammalian cell membrane, we exposed canine red blood cells (RBCs) in PBS solutions. The healthy RBC has biconcave morphology, as shown in Figure 2(a) "Control," which gives elastic and biorheological properties.
The shape and deformability are essential features of their biological functions. Figure 2(a) "Air P" and " $\mathrm{N}_{2} \mathrm{P}$ " show the morphological changes of RBCs in response to the APPJ treatment for 1,3 , and 5 min with air and $\mathrm{N}_{2}$ gases, respectively. With air APPJ treatment, RBCs were shrunken after $1 \mathrm{~min}$, and finally became round after $5 \mathrm{~min}$. In contrast, with $\mathrm{N}_{2}$ APPJ treatment, RBCs became spiculated with plasma exposure time. These different morphological changes should be attributed to different chemical components in the solutions coming from air and $\mathrm{N}_{2}$ plasma.

It has been known that a variety of agents can modify the shape of RBCs [16]. One set of agents, including anionic amphipaths, high salt, high $\mathrm{pH}$, ATP depletion, and cholesterol enrichment, induces spiculated shapes, called echinocytes. Another set of agents, including cationic amphipaths, low salt, low $\mathrm{pH}$, and cholesterol depletion, induces concave shapes, called stomatocytes. Further loading with both types of agents induces budding off the membrane, resulting in spherical bodies. Our air APPJ treatment induced RBCs to form stomatocyte-like structures, while $\mathrm{N}_{2}$ APPJ treatment induced echinocyte-like structures. Considering previous findings, air APPJ might reduce the area of outer membrane or increase the area of inner membrane, while $\mathrm{N}_{2}$ APPJ might do the opposite [16].

As RBC morphology determines the rheological properties, their deformability was measured after APPJ treatment. Figure 2(b) demonstrates an elongation index (EI) representing RBC deformability determined from the diffraction 
image of RBCs at a shear stress of $3 \mathrm{~Pa}$. The shape of RBCs when exposed to air plasma jet tends to become gradually spherical, which indicates a reduction in RBC deformability. The EI values of the RBCs exposed to the air plasma for 1,3 , and $5 \mathrm{~min}$ were $54 \%, 85 \%$, and $87 \%$, which provide lower values of deformability than the control sample $(\mathrm{EI}=0.311)$, respectively. The EI values of $\mathrm{N}_{2}$ plasma-exposed RBCs at 1,3 , and $5 \mathrm{~min}$ were $0.010,0.007$, and 0.061 , respectively, which were $21 \%, 28 \%$, and $68 \%$ lower values of deformability than the control sample (0.311). In general, the EI values of plasma-exposed RBCs at different exposure times were lower than those of the control sample that had an elliptic shape. We observed that the RBC membrane hardness exposed to $\mathrm{N}_{2}$ plasma was less than that exposed to air plasma at each exposure time. A similar reduction of EI value was also reported in a previous study with a dielectric barrier discharge [17].

In addition, we observed differential color changes of RBCs after air and $\mathrm{N}_{2}$ APPJ treatment (Figure 2(c)), which implied the oxidation of intracellular hemoglobins ( $\mathrm{Hbs}$ ). This intracellular oxidation implies the penetration of ROS/ RNS through the membrane. In order to examine the effects of APPJ on membrane integrity, we examined the hemolysis by measuring the absorption of Hbs leaked out from RBCs (Figure 2(d)). While the values increased in both gas APPJ treatments, air APPJ induced more leakage in the RBC membranes. In previous studies, RBCs from hemolytic anemia patients were measured to have increased membrane stiffness, as well as reduced deformability $[18,19]$. Therefore, we tried to confirm the increase of elastic moduli of RBCs by using AFM nanoindentation methods. However, the elastic moduli were estimated larger in air APPJ-treated RBCs, but smaller in $\mathrm{N}_{2}$ APPJ-treated RBCs, compared to normal RBCs (Supporting Information, Figure S1 available online at https://doi.org/10.1155/2017/1289041). These values were measured by point indentation by sharp AFM cantilever, so they could be different from the EI value, which represents whole-cell structural deformation. The echinocyte-like structures acquired after $\mathrm{N}_{2}$ APPJ treatment may be related to reduced volume or inner pressure, which might be related to the reduced elasticity. Stomatocyte-like structures acquired after air APPJ treatment may have opposite characteristics.

In summary, both air and $\mathrm{N}_{2}$ APPJ reduced deformability and increased hemolysis in a time-dependent manner. Air APPJ showed more reduction in those measurements for the same exposure duration, which implied the membrane integrity was damaged more severely with $\mathrm{N}_{2}$ and $\mathrm{O}_{2}$ simultaneous discharges. Their differential changes in morphology and color suggest differential chemical reactions in these two conditions.

\subsection{Characterization of Chemical Changes of $R B C$} Lipid-NMR Spectroscopy. Though damages in cytoskeletal proteins, such as spectrin, actin, and band 3, could also lead to structural deformation [20], we first focused on the chemical changes in membrane lipids, because of their vulnerability to oxidative stress. The ${ }^{1} \mathrm{H}$ NMR spectra of the total lipid extracted from the RBCs show detailed molecular changes after 5 min of APPJ treatment [21,22]. Figure 3(a) shows NMR spectra in the range of 0.5 and $6.0 \mathrm{ppm}$, since there were no clear peaks over $6 \mathrm{ppm}$ chemical shift. The peaks of control, $\mathrm{N}_{2}$ plasma-treated, and air plasma-treated RBCs were overlapped well below $3.0 \mathrm{ppm}$, where the peaks were generally attributed to fatty acids and ergosterols. The peak areas were integrated, proton numbers being normalized by the peak area at $0.88 \mathrm{ppm}$ representing $\left[-\mathrm{CH}_{3}\right]$ as 6 , and are shown in the table of Figure 3(b). The proton numbers at $1.26 \mathrm{ppm}$ representing $\left[-\left(\mathrm{CH}_{2}\right)_{\mathrm{n}}{ }^{-}\right]$were reduced after both $\mathrm{N}_{2}$ and air APPJ treatment from 25 to 22 . This means the reduction of fatty acid chain length by plasma treatment. There were more significant reductions at $1.59 \mathrm{ppm}$ representing $\left[-\mathrm{CO}-\mathrm{CH}_{2}-\mathrm{CH}_{2}-\right]$, where the number of protons was measured as 53,41 , and 52 for control, $\mathrm{N}_{2}$ plasmatreated, and air plasma-treated RBCs, respectively. This implies the chemical changes of glycerol or fragmentation of phospholipids between fatty acid and glycerol. It is notable that $\mathrm{N}_{2}$ APPJ caused more severe effects on these changes.

Figure 3(c) shows the spectra between 3.0 and $6.0 \mathrm{ppm}$, where the positions of the peaks are largely changed. Some peaks have almost disappeared (marked with blue numbers in Figure 3(b)), and some have become relatively dominant after plasma treatment (marked with red numbers in Figure 3(b)). Peaks in this range are generally attributed to protons at phospholipid head groups and glycerol backbones. The chemical shift value of each peak is marked on the graph. In both $\mathrm{N}_{2}$ and air APPJ treatments, peaks at 3.26 and $3.65 \mathrm{ppm}$ are significantly reduced, which represent ${ }^{1} \mathrm{H}$ at the choline $\left[-\mathrm{N}\left(\mathrm{CH}_{3}\right)_{3}\right]$ of phosphatidylcholine or sphingomyelin. In contrast, peaks at $3.16 \mathrm{ppm}$ are significantly enhanced after only $\mathrm{N}_{2}$ APPJ treatments, which represents $\left[-\mathrm{CH}_{2} \mathrm{NH}_{3}^{+}\right]$of phosphatidylethanolamine. Chemical reactions might possibly occur between the phospholipids and ammonium ions from $\mathrm{N}_{2}$ APPJ.

Peaks between 3.73 and $5.22 \mathrm{ppm}$ are generally related to the glycerol backbone, which connects the head and tail groups of the phospholipid. Most peaks remain after the plasma treatment; however, their relative ratio has changed. Peaks at 3.73 and $3.86 \mathrm{ppm}$ are reduced by both plasma conditions, representing phosphatidylglycerol. However, peaks at 4.12 and $4.40 \mathrm{ppm}$ are significantly reduced by only air plasma condition, representing glycerol Sn1 methylene protons. Sn1 carbon is connected to one part of acyl chains as Sn2 carbon, but it is more exposed to outer attacks, such as ROS from APPJ. In addition, a peak at $5.16 \mathrm{ppm}$ newly appears in the case of air plasma treatment, which represents glycerol Sn2 protons connected to ether lipids. It is also notable that the peak at $5.37 \mathrm{ppm}$ representing unsaturated fatty acid is almost conserved, and no significant peaks at 9.7 and $11 \mathrm{ppm}$ representing aldehyde or carboxyl groups separately are observed.

In summary, our results imply that the outer head groups of the phospholipids or glycerols are vulnerable to the plasma treatment, as compared to the fatty acid tail groups inside the membrane, especially to air APPJ. The high power of removing the head group of phospholipids of air APPJ may result in reduction of the outer leaflet and following stomatocyte-like distortion. Likewise, the addition of ammonium ions on the 


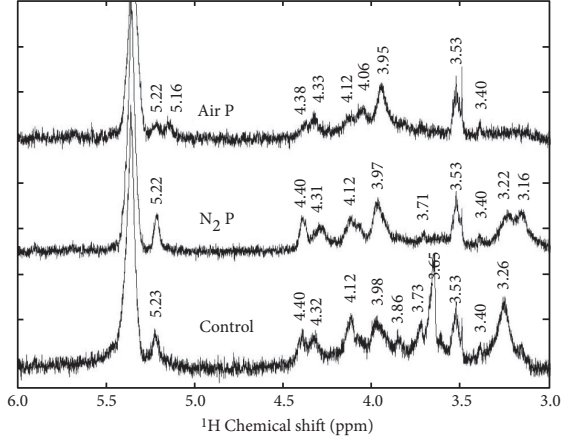

(a)

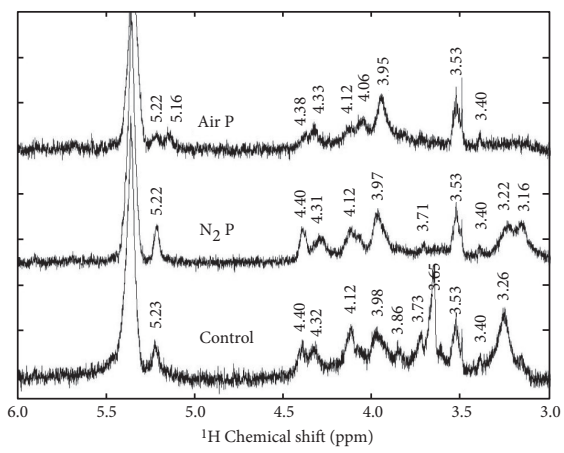

(c)

\begin{tabular}{|c|c|c|c|c|c|}
\hline$\delta(\mathrm{ppm})$ & & & Control & $\mathrm{N}_{2} \mathrm{P}$ & Air $\mathrm{P}$ \\
\hline 0.69 & $-\mathrm{C}_{18 \mathrm{H}_{3}}$ & Ergosterol & 1.1 & 1.1 & 1.0 \\
\hline 0.88 & $-\mathrm{CH} 3$ & Fatty acid & 6.0 & 6.0 & 6.0 \\
\hline 0.93 & $-\mathrm{C}_{21} \mathrm{H}_{3}$ & Ergosterol & 2.4 & 1.4 & 1.5 \\
\hline 1.02 & $-\mathrm{C}_{19} \mathrm{H}_{3}$ & Ergosterol & 2.4 & 2.2 & 2.0 \\
\hline 1.26 & $-\left(\mathrm{CH}_{2}\right)_{\mathrm{n}^{-}}$ & Fatty acid & 24.5 & 21.5 & 22.3 \\
\hline 1.59 & $-\mathrm{CH}_{2} \mathrm{CH}_{2} \mathrm{COO}-$ & Fatty acid & 52.5 & 40.6 & 52.0 \\
\hline 1.85 & $-\left(\mathrm{CH}_{2}\right)_{\mathrm{n}^{-}}$ & Fatty acid & 2.0 & 1.1 & 1.0 \\
\hline 2.02 & $-\mathrm{CH}_{2} \mathrm{HC}=$ & Fatty acid & 3.8 & 3.0 & 2.8 \\
\hline 2.29 & $-\mathrm{CH}_{2} \mathrm{CO}-$ & Fatty acid & 2.2 & 2.2 & 1.8 \\
\hline 2.88 & $=\mathrm{CHCH}_{2} \mathrm{CH}=$ & Fatty acid & 1.1 & 1.4 & 1.3 \\
\hline 3.16 & $-\mathrm{CH}_{2} \mathrm{NH}_{3}+$ & PE head group & 0.0 & 0.5 & 0.0 \\
\hline 3.26 & $-\mathrm{N}+\left(\mathrm{CH}_{3}\right)_{3}$ & PC head group & 0.9 & 0.8 & 0.0 \\
\hline 3.53 & $-\mathrm{CH}_{2} \mathrm{CHCH}_{2^{-}}$ & Glycerol of PG & 0.4 & 0.5 & 0.5 \\
\hline 3.65 & $-\mathrm{CH}_{2} \mathrm{~N}+\left(\mathrm{CH}_{3}\right)_{3}$ & SM/PC head group & 0.7 & 0.0 & 0.0 \\
\hline 3.73 & $-\mathrm{CH}_{2} \mathrm{CHCH}_{2^{-}}$ & Glycerol of PG & 0.2 & 0.0 & 0.0 \\
\hline 3.86 & $-\mathrm{CH}_{2} \mathrm{CHCH}_{2}-$ & Glycerol of PG & 0.2 & 0.0 & 0.0 \\
\hline 3.98 & $-\mathrm{CH}_{2} \mathrm{CHCH}_{2-}$ & Glycerol Sn3 & 0.7 & 0.8 & 0.8 \\
\hline 4.06 & $-\mathrm{OCH}_{2} \mathrm{CH}_{2} \mathrm{NH}_{3}+$ & Phead group & 0.0 & 0.3 & 0.4 \\
\hline 4.12 & $-\mathrm{CH}_{2} \mathrm{CHCH}_{2-}$ & Glycerol Sn1 & 0.4 & 0.5 & 0.0 \\
\hline 4.32 & $-\mathrm{CH}_{2} \mathrm{CHCH}_{2}{ }^{-}$ & Triglyceride & 0.2 & 0.5 & 0.3 \\
\hline 4.40 & $-\mathrm{CH}_{2} \mathrm{CHCH}_{2^{-}}$ & Glycerol Sn1 & 0.2 & 0.3 & 0.0 \\
\hline 5.16 & $-\mathrm{CH}_{2} \mathrm{CHCH}_{2-}$ & Glycerol Sn2 (ether) & 0.0 & 0.0 & 0.1 \\
\hline 5.22 & $-\mathrm{CH}_{2} \mathrm{CHCH}_{2^{-}}$ & Glycerol Sn2 (diacyl) & 0.2 & 0.3 & 0.1 \\
\hline 5.37 & $-\mathrm{HC}=\mathrm{CH}-$ & Fatty acid & 2.2 & 2.7 & 2.5 \\
\hline
\end{tabular}

(b)

FIGURE 3: NMR spectroscopy of RBCs after air and $\mathrm{N}_{2}$ APPJ treatment. (a-b) NMR spectroscopy of RBC lipid extracts in the range between 0.5 and $6.0 \mathrm{ppm}$ and 3.0 and 6.0 chemical shifts, respectively, and (c) assignments of chemical shifts and the proton number for each peak analyzed by peak area.

head group may be the reason for echinocyte-like distortion of RBCs by $\mathrm{N}_{2}$ APPJ.

\subsection{Characterization of Chemical Changes of RBC-Raman} Spectroscopy. In order to obtain chemical changes in whole RBCs, we tried Raman spectroscopy with 488, 532, and $633 \mathrm{~nm}$ lasers. Different excitation wavelengths bring differential Raman spectra of RBCs, due to the specific absorption bands of RBCs [23]. In previous reports, the main Raman spectral bands of RBCs were mostly assigned to hemoglobin vibration energy, and some were to cell membrane lipids and proteins $[23,24]$. Figure 4 shows the Raman spectra of RBCs after 5 minutes of APPJ treatment. The main bands were from hemoglobin (marked with "Hb" in the figure) in the region of $1340-1380 \mathrm{~cm}^{-1}$ corresponding to various pyrrole ring vibration modes and $1500-1640 \mathrm{~cm}^{-1}$ corresponding to the combination of spin state marker vibration modes. Peaks at $752 \mathrm{~cm}^{-1}$ and $798 \mathrm{~cm}^{-1}$ correspond to ring breathing, while peaks at $934 \mathrm{~cm}^{-1}$ and $674 \mathrm{~cm}^{-1}$ correspond to ring symmetric stretch and deformations of $\mathrm{Hb}$. The protein bands (marked with "mem" in the figure) include mainly the amide I band at $1648 \mathrm{~cm}^{-1}$ and several low peaks of $\mathrm{CH}_{2} / \mathrm{CH}_{3}$ deformation modes primarily from amino acid side chains at $1448 \mathrm{~cm}^{-1}, \mathrm{CH}_{2}$ twist mode at $1324 \mathrm{~cm}^{-1}$, skeletal vibrations at $973 \mathrm{~cm}^{-1}$, and $\mathrm{C}-\mathrm{C}$ stretch of phenylalanine ring at $998 \mathrm{~cm}^{-1}$. The lipid bands (marked with "mem" in the figure) include the acyl chain stretch modes at 2850-3000 and 1060$1180 \mathrm{~cm}^{-1}$ and $\mathrm{CH}_{2} / \mathrm{CH}_{3}$ deformation modes at $1448 \mathrm{~cm}^{-1}$.
Figure 4(i) shows that both air and $\mathrm{N}_{2}$ APPJ treatment induced slight intensity changes, rather than frequency modulations. Figure 4(ii) shows enlarged graphs in the region of $900-1700 \mathrm{~cm}^{-1}$, and Figure 4(iii) shows graphs that reveal deviations of the spectra between plasma-treated samples and control, respectively. The peaks whose differences are noticeable are marked with up or down arrows in Figure 4(ii), and center wavenumber values are marked in Figure 4(iii).

In the case of $488 \mathrm{~nm}$ laser (Figure 4(a)), the peak at $1110 \mathrm{~cm}^{-1}$ became lower (corresponding to acyl chain stretch $\downarrow)$, the peak at $1370 \mathrm{~cm}^{-1}$ became sharper and higher (corresponding to pyrrol ring vibration: $1355 \mathrm{~cm}^{-1}$ representing $\mathrm{Fe}^{2+} \downarrow$ and $1375 \mathrm{~cm}^{-1}$ representing $\mathrm{Fe}^{3+} \uparrow$ ), and the wide band of multiple peaks at $1550-1650 \mathrm{~cm}^{-1}\left(1530 \mathrm{~cm}^{-1}\right.$ for $\mathrm{C}=\mathrm{C} \operatorname{Trp} \downarrow, 1545 \mathrm{~cm}^{-1}$ for $\mathrm{Fe}^{2+} \downarrow, 1608 \mathrm{~cm}^{-1}$ for $\mathrm{Fe}^{2+} \downarrow$, and $1642 \mathrm{~cm}^{-1}$ for $\mathrm{Fe}^{3+} \uparrow$ ) were modified by air APPJ treatment [24]. The peak at $2712 \mathrm{~cm}^{-1}$ was an overtone of $1355 \mathrm{~cm}^{-1}$, whose intensities reduced together. $\mathrm{N}_{2}$ APPJ treatment reduced peaks at $1583 \mathrm{~cm}^{-1}$, which also represented the reduction of $\mathrm{Fe}^{2+}-\mathrm{Hb}$.

With $532 \mathrm{~nm}$ laser (Figure 4(b)), the spectral changes were similar to those with $488 \mathrm{~nm}$ laser. Acyl chain length may be shortened $\left(1130 \mathrm{~cm}^{-1} \downarrow\right)$, and iron of $\mathrm{Hb}$ may be oxidized to $\mathrm{Fe}^{3+}\left(1545\right.$ and $1601 \mathrm{~cm}^{-1} \mathrm{Fe}^{2+} \downarrow$ and $1637 \mathrm{~cm}^{-1}$ $\left.\mathrm{Fe}^{3+} \uparrow\right)$ by air APPJ treatment. In addition, the sharp reduction at $752 \mathrm{~cm}^{-1}$ was related to the reduction of porphyrin breathing mode of $\mathrm{Hb}$, which represents the viability of RBCs 


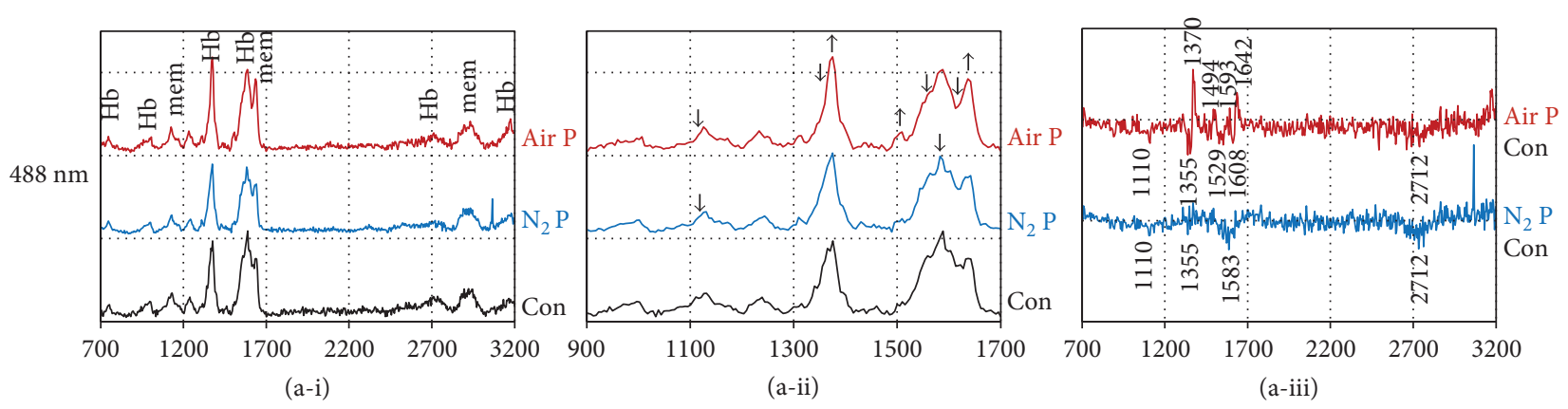

(a)

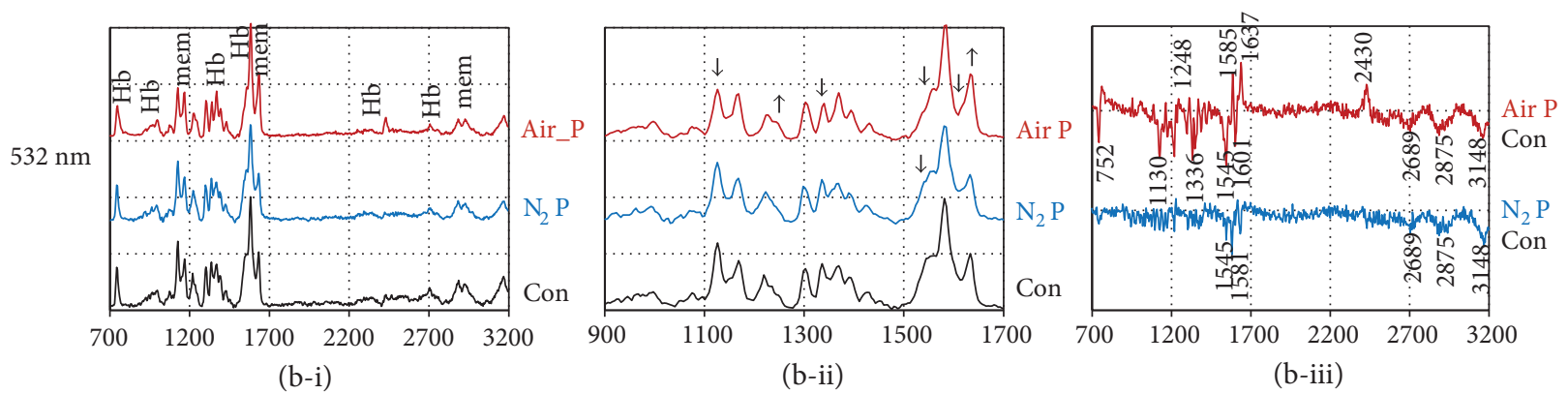

(b)

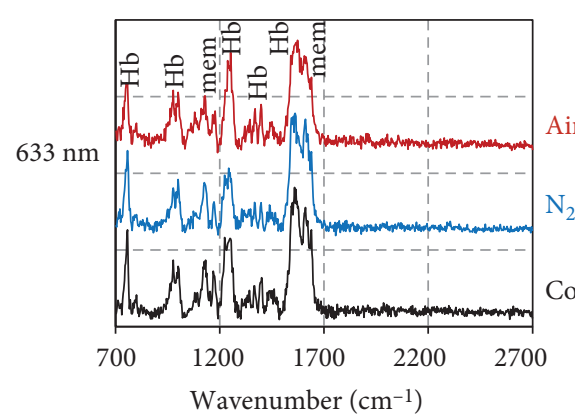

$(\mathrm{c}-\mathrm{i})$

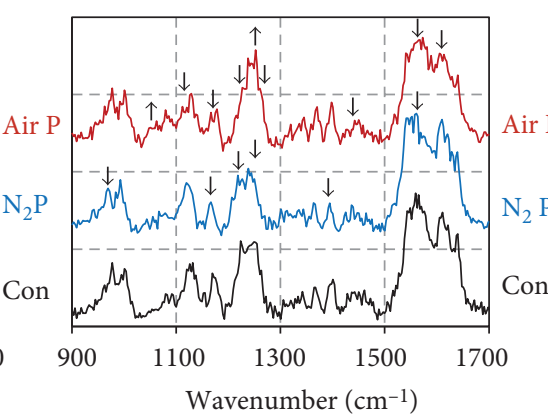

(c-ii)

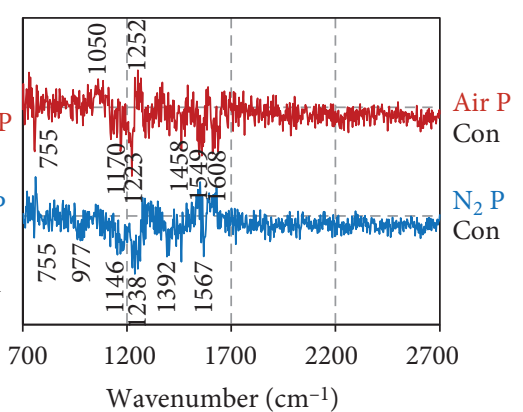

(c-iii)

(c)

FIGURE 4: Raman spectroscopy of RBCs after air and $\mathrm{N}_{2}$ APPJ treatment using excitation lasers with wavelengths of (a) $488 \mathrm{~nm}$, (b) $532 \mathrm{~nm}$, and (c) $633 \mathrm{~nm}$. The Raman spectra of control RBCs, air APPJ-treated RBCs, and $\mathrm{N}_{2}$ APPJ-treated RBCs were displayed in the ranges of (i) $700-3200 \mathrm{~cm}^{-1}$ and (ii) $900-1700 \mathrm{~cm}^{-1}$ wave numbers, and (iii) the differences between APPJ-treated samples and control were separately displayed.

[25]. The enhancement of peak at $1248 \mathrm{~cm}^{-1}$ was related to the protein denaturation/heme aggregation, and that of the peak at $2430 \mathrm{~cm}^{-1}$ was related to the increase of hydrogen bonds of O-H...O type $[26,27]$. The reduction in $2875-2915 \mathrm{~cm}^{-1}$ represented the reduced amount of $\mathrm{CH}_{2}$ or $\mathrm{CH}_{3}$ groups of acyl chains. Raman spectra of RBCs treated by $\mathrm{N}_{2}$ APPJ shows less difference to control, which means less impact on the lipid membrane and the $\mathrm{Hb}$ spin state by $\mathrm{N}_{2}$ APPJ.

With $633 \mathrm{~nm}$ laser (Figure 4(c)), the spectra patterns of air and $\mathrm{N}_{2}$ APPJ-treated RBCs showed the most difference from each other. As observed with 488 and $514 \mathrm{~nm}$ lasers, air APPJ treatment shortened the acyl chain length (1150$\left.1170 \mathrm{~cm}^{-1} \downarrow\right)$, and reduced $\mathrm{O}_{2}$-bound $\mathrm{Hb}(1223,1549$, and $1608 \mathrm{~cm}^{-1} \downarrow$ ). Air APPJ treatment also enhanced the peaks at $1252 \mathrm{~cm}^{-1}$, which is rather strongly observed in met-Hb. $\mathrm{N}_{2}$ APPJ treatment also reduced the acyl chain length
(1150-1170 $\left.\mathrm{cm}^{-1} \downarrow\right)$. In addition, $\mathrm{N}_{2}$ APPJ treatment enhanced the peaks at 1549 and $1608 \mathrm{~cm}^{-1}$ and reduced the peaks at $977,1238,1392$, and $1567 \mathrm{~cm}^{-1}$, which related to the reduction of $\mathrm{O}_{2}$-bound $\mathrm{Hb}$ [28].

Overall, Raman spectroscopy data show that both gas APPJs can affect the lipid membrane and even modify the spin states of intracellular $\mathrm{Hb}$. It was difficult to discern peaks associated with proteins separately. APPJ reduced the length of acyl chains of lipid membrane, and reduced the $\mathrm{O}_{2}$-bound $\mathrm{Hbs}$ to $\mathrm{O}_{2}$-detached form, or further to met- $\mathrm{Hb}\left(\mathrm{Fe}^{3+} \mathrm{Hb}\right.$ without oxygen). Additionally, we analyzed them using PCA (Figure S2). This qualitative multivariate analysis helped us to discriminate one sample from the others. We performed PCA for RBC samples exposed to air APPJ, $\mathrm{N}_{2}$ APPJ, and $\mathrm{H}_{2} \mathrm{O}_{2}$. Four groups (control, air APPJ, $\mathrm{N}_{2}$ APPJ, and $\mathrm{H}_{2} \mathrm{O}_{2}$ ) seemed to be distinctly classified, but the boundary of control 

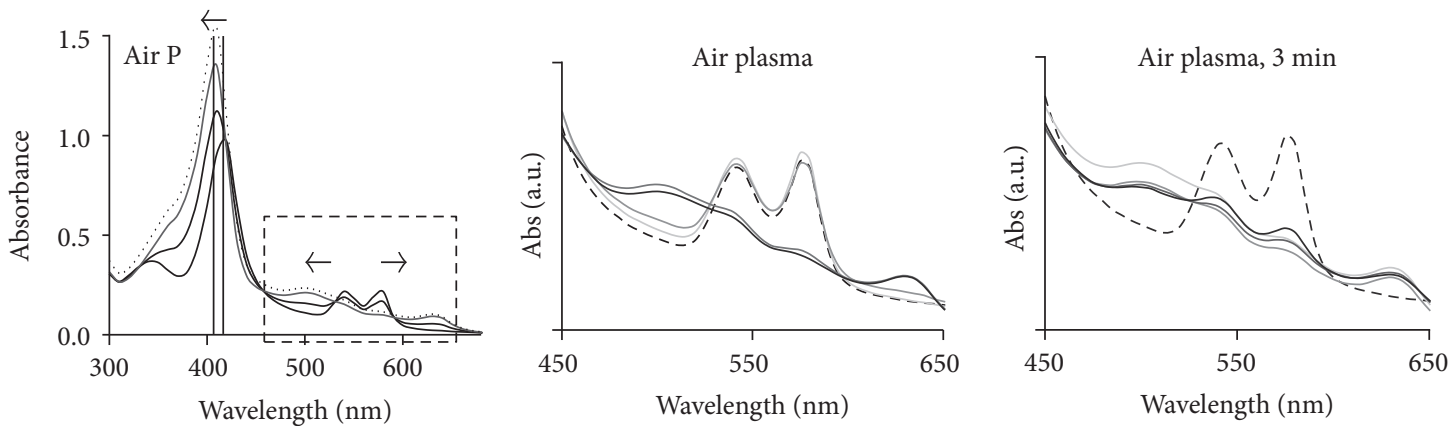

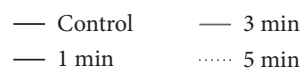

(a)

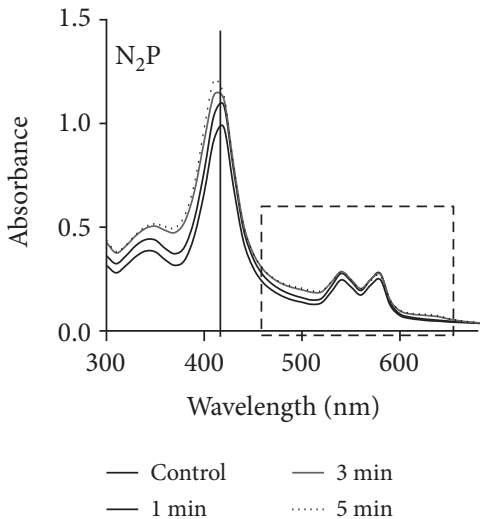

(b)

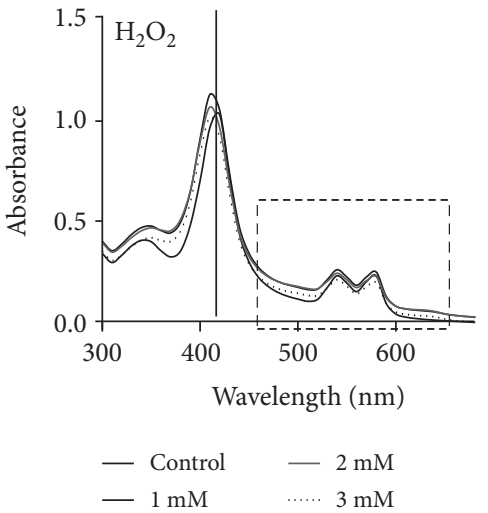

(c)

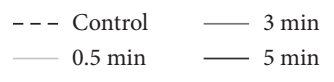

(d)

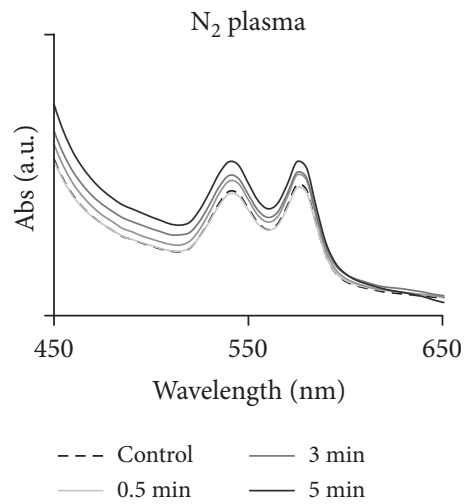

(e)
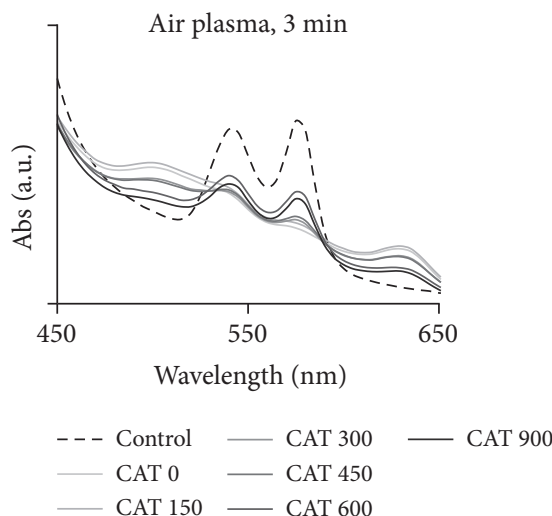

(f)

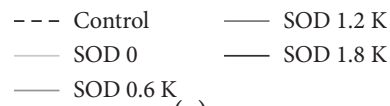

(g)

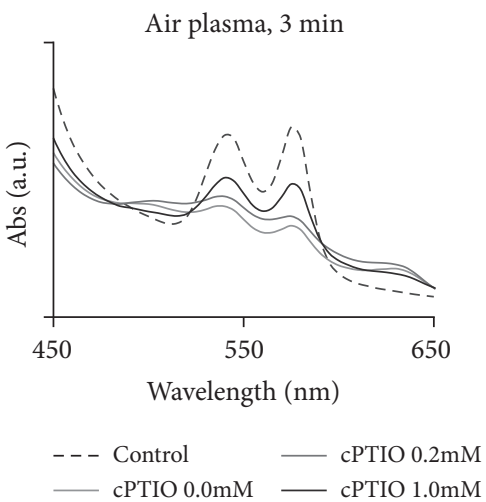

(h)
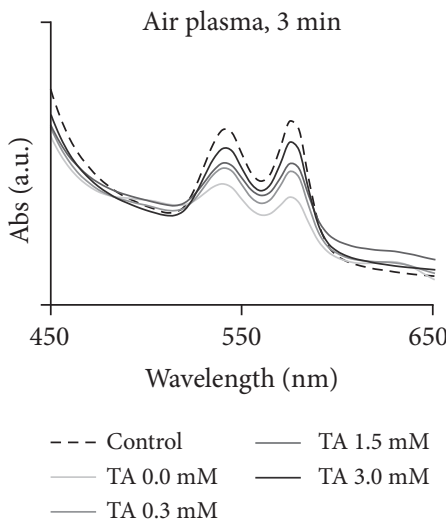

(i)

FIGURE 5: (a-c) Absorption spectroscopy of air and $\mathrm{N}_{2}$ APPJ-treated RBCs and $\mathrm{H}_{2} \mathrm{O}_{2}$-treated RBCs, respectively, in the range of 300-650 nm. (d-e) Absorption spectroscopy of air and $\mathrm{N}_{2}$ APPJ-treated RBCs, respectively, in the range of 450-650 nm wavelengths. (f-i) Absorption spectroscopy of air APPJ-treated RBCs for 3 min with several antioxidant chemicals.

and $\mathrm{N}_{2}$ plasma-exposed $\mathrm{RBC}$ samples was found to be ambiguous. The result was the same when we tried the same analysis with lipid membrane ghosts from RBCs. These analyses suggest that air APPJ made distinct effects in comparison to $\mathrm{N}_{2}$ APPJ or $\mathrm{H}_{2} \mathrm{O}_{2}$, and the $\mathrm{N}_{2}$ APPJ made less change in the molecules of RBCs than air APPJ.

3.5. Oxidation of Intracellular Hemoglobin-Absorption Spectroscopy. Hbs in RBCs have specific absorption bands of light, which bring red color to RBCs. Figure 2(b) shows that the air APPJ-treated RBCs are brownish color, but $\mathrm{N}_{2}$ APPJ-treated RBCs are still red. The changes in absorption band denote the oxidation of Hbs in RBCs. Figures 5(a), $5(b)$, and 5(c) show the optical absorption spectra of RBCs between 300 and $650 \mathrm{~nm}$ according to the APPJ treatment time. Oxygen-bound $\mathrm{Hb}$ has three main absorption bands at about 415 (soret or B-bands), $540\left(\mathrm{Q}_{\mathrm{v}}\right.$ or $\alpha$ band), and $575 \mathrm{~nm}\left(\mathrm{Q}_{0}\right.$ or $\beta$ band $)$ [22]. Air APPJ changes these three 
peaks severely (Figure 5(a)). The absorption bands are shifted from 415 to $408 \mathrm{~nm}$, from 540 to $499 \mathrm{~nm}$, and from 575 to $630 \mathrm{~nm}$ with air APPJ treatment time. These peak shifts are assigned to the $\mathrm{Fe}^{3+} \mathrm{Hbs}$ without oxygen (met-Hb), which are the oxidized form of $\mathrm{Hbs}$ by reactive species from air APPJ [29]. In contrast, the changes by 5 min of $\mathrm{N}_{2}$ APPJ or by $3 \mathrm{mM} \mathrm{H} \mathrm{H}_{2} \mathrm{O}_{2}$ are comparatively negligible (Figures 5(b) and $5(\mathrm{c})$ ). The enlarged absorption spectra in the range of 450 to $650 \mathrm{~nm}$ confirm these observations (Figures 5(d) and 5(e)). Air APPJ has the potential to oxidize Hbs inside RBCs to met-Hbs with longer than 3 min exposure, while $\mathrm{N}_{2}$ APPJ does not.

In order to examine which reactive species were responsible for the met-Hb formation by air APPJ, we added several antioxidants to the RBC homogenates when they were exposed to air APPJ for $3 \mathrm{~min}$. Figures 5(f), 5(g), $5(\mathrm{~h})$, and 5(i) show the absorption spectra of air APPJtreated RBCs with catalase (CAT), superoxide dismutase (SOD), carboxy-PTIO (cPTIO), and terephthalic acid (TA), respectively. CAT is a well-known scavenger for $\mathrm{H}_{2} \mathrm{O}_{2}$, cPTIO for NO, SOD for $\mathrm{O}_{2}{ }^{*}$, and TA for $\mathrm{OH}$. radicals. The spectra were displayed according to the increase of concentrations of each scavenger in the graphs. All scavengers alleviated the oxidation of RBCs; however, cPTIO and TA seemed more effective. The spectra remained at some level, even with high amount of CAT or SOD, which meant their reducing effects on $\mathrm{Hb}$ oxidation were limited to some levels. In contrast, the spectra recovered similar to control when cPTIO or TA was added, which implied $\mathrm{NO} \bullet$ and $\mathrm{OH} \bullet$ played major roles in $\mathrm{Hb}$ oxidations by air APPJ.

The chemical analysis of APPJ-treated solutions showed that $\mathrm{N}_{2}$ APPJ produced more amounts of $\mathrm{OH} \bullet$ and $\mathrm{H}_{2} \mathrm{O}_{2}$, while air APPJ produced more amount of NO• in PBS solutions (Figure 1(c)). This implies that NO- plays the most important roles in air APPJ induced intracellular $\mathrm{Hb}$ oxidation. Though $\mathrm{NO} \bullet$ is a relatively stable radical, it still has the power to modify biological molecules. $\mathrm{NO} \bullet$ reacts rapidly with $\mathrm{O}_{2}$-bound $\mathrm{Hb}$, resulting in met-Hbs and nitrate; reacts with $\mathrm{Hb}$, resulting in nitrosyl$\mathrm{Hbs}$; and reacts with met-Hbs, resulting in $\mathrm{Hb}$ and nitric oxide cation [30, 31]. Thus, the lifetime of NO• in aqueous solution is about several min, about several sec in tissues, and about millisec in blood vessels [32]. In the case of $\mathrm{OH} \bullet$ radicals, it would be hard for them to directly interact with RBCs, due to their short lifetime of about nanoseconds. The effects of TA in our experiment may be attributed to scavenging the $\mathrm{OH} \bullet$ radicals reverted through Fenton reactions from their stabilized molecule $\mathrm{H}_{2} \mathrm{O}_{2}[10]$.

Due to the high affinity of $\mathrm{Hbs}$ with $\mathrm{NO} \bullet$, RBCs have regulatory roles in the modulation of intravascular NO•. However, intravascular hemolysis releases $\mathrm{Hbs}$ into the plasma compartment, resulting in rapid rates of NO• consumption. Consequently, vascular relaxation and vasodilation are inhibited. It was reported that administration of blood $\mathrm{Hb}$ substitute solutions in clinical trials led to pulmonary and systemic hypertension, increased systemic vascular resistance, decreased organ perfusion and gastrointestinal paresis, and increased rates of death in trauma patients [33]. APP treatment initiates multiple mechanisms through chemical oxidation/nitrosation of biomolecules in anticancer action, DNA transfection, and so forth. However, the RBC hemolysis can induce toxicity in tissue or whole-body damage through $\mathrm{Hbs}$ release into tissue or blood flow. Therefore, the exact estimation of cytotoxicity by APPJ should be systemically investigated [34-36].

\section{Conclusions}

In conclusion, both air and $\mathrm{N}_{2}$ APPJ have been shown to be able to induce morphological and hemolytic changes of RBCs in a time-dependent manner. Though $\mathrm{N}_{2}$ APPJ generates higher amounts of $\mathrm{OH} \bullet$ and $\mathrm{H}_{2} \mathrm{O}_{2}$ oxidants, air APPJ elicits changes in RBCs at much shorter time through severe damage of the lipid membrane. In addition, air APPJ can alter intracellular $\mathrm{O}_{2}$ bound $\mathrm{Hbs}$ to met-Hbs, which loses $\mathrm{O}_{2}$ carrying potential. NO• generated in air APPJ may play critical roles in APPJ-induced cellular toxicity, including hemolysis, and iron-containing molecular oxidations. These results provide a useful biological model to estimate APPJ toxicity and provide insight into APPJ cytotoxicity in biological applications.

\section{Conflicts of Interest}

The authors declare no competing financial interests.

\section{Acknowledgments}

This work was financially supported by a grant from the National Research Foundation of Korea (NRF), funded by the Korean government (MSIP) (NRF-2010-0027963 and NRF- NRF-2016R1A1A1A05005431).

\section{References}

[1] M. Keidar, "Plasma for cancer treatment," Plasma Sources Science and Technology, vol. 24, no. 3, p. 033001, 2015.

[2] O. J. Lee, H. W. Ju, G. Khang et al., "An experimental burn wound-healing study of non-thermal atmospheric pressure microplasma jet arrays," Journal of Tissue Engineering and Regenerative Medicine, vol. 10, no. 4, pp. 348-357, 2016.

[3] S. Fathollah, S. Mirpour, P. Mansouri et al., "Investigation on the effects of the atmospheric pressure plasma on wound healing in diabetic rats," Scientific Reports, vol. 6, article no. 19144, 2016.

[4] K. Panngom, K. Y. Baik, M. K. Nam, J. H. Han, H. Rhim, and E. H. Choi, "Preferential killing of human lung cancer cell lines with mitochondrial dysfunction by nonthermal dielectric barrier discharge plasma," Cell Death Diseases, vol. 4, no. 5, p. e642, 2013.

[5] T. Takamatsu, K. Uehara, Y. Sasaki et al., "Investigation of reactive species using various gas plasmas," RSC Advances, vol. 4, no. 75, p. 39901, 2014.

[6] K. Y. Baik, Y. H. Kim, Y. H. Ryu et al., "Feeding-gas effects of plasma jets on Escherichia coli in physiological solutions," 
Plasma Processes and Polymers, vol. 10, no. 3, pp. 235-242, 2013.

[7] K. Wende, P. Williams, J. Dalluge et al., "Identification of the biologically active liquid chemistry induced by a nonthermal atmospheric pressure plasma jet," Biointerphases, vol. 10, no. 2, p. 029518, 2015.

[8] S. Bekeschus, A. Schmidt, L. Bethge et al., "Redox stimulation of human THP-1 monocytes in response to cold physical plasma," Oxidative Medicine and Cellular Longevity, vol. 2016, Article ID 5910695, 11 pages, 2016.

[9] A. Ali, Z. Ashraf, N. Kumar et al., "Influence of plasmaactivated compounds on melanogenesis and tyrosinase activity," Scientific Reports, vol. 6, article no. 21779, 2016.

[10] M. Y. B. Cimen, "Free radical metabolism in human erythrocytes," Clinica Chimica Acta, vol. 390, no. 1-2, pp. 1-11, 2008.

[11] C. S. S. S. Reddy, M. V. V. Subramanyam, R. Vani, and S. Asha Devi, "In vitro models of oxidative stress in rat erythrocytes: effects of antioxidant supplements," Toxicology In Vitro, vol. 21, no. 8, pp. 1355-1364, 2007.

[12] L.-M. Chi, W. Wu, K.-L. P. Sung, and S. Chien, "Biophysical correlates of lysophosphatidylcholine- and ethanolmediated shape transformation and hemolysis of human erythrocytes. Membrane viscoelasticity and NMR measurement," Biochimica et Biophysica Acta, vol. 1027, no. 2, pp. 163-171, 1990.

[13] G. B. Sim, A Study on the Atmospheric Pressure Plasma Electrical and Optical Characteristic for Biomedical Application, Master Thesis, Kwangwoon University, Seoul, Korea, 2014.

[14] E. G. Baligh and W. J. Dyer, "A rapid method of total lipid extraction and purification," Canadian Journal of Biochemistry and Physiology, vol. 37, no. 8, pp. 911-917, 1959.

[15] S. Shin, J. Hou, J. Suh, and M. Singh, "Validation and application of a microfluidic ektacytometer (RheoScan-D) in measuring erythrocyte deformability," Clinical Hemorheology and Microcirculation, vol. 37, no. 4, pp. 319-328, 2007.

[16] H. W. G. Lim, M. Wortis, and R. Mukhopadhyay, "Stomatocyte-discocyte-echinocyte sequence of the human red blood cell: evidence for the bilayer-couple hypothesis from membrane mechanics," Proceedings of the National Academy of Sciences of the United States of America, vol. 99, no. 26, pp. 16766-16769, 2002.

[17] J. Kim, J. H. Kim, B. Chang, E. H. Choi, and H. K. Park, "Hemorheological alterations of red blood cells induced by non-thermal dielectric barrier discharge plasma," Applied Physics Letters, vol. 109, no. 19, p. 193701, 2016.

[18] I. Dulin'ska, M. Targosz, W. Strojny et al., "Stiffness of normal and pathological erythrocytes studied by means of atomic force microscopy," Journal of Biochemical and Biophysical Methods, vol. 66, no. 1-3, pp. 1-11, 2006.

[19] X. Chen, L. Feng, H. Jin, S. Feng, and Y. Yu, "Quantification of the erythrocyte deformability using atomic force microscopy: correlation study of the erythrocyte deformability with atomic force microscopy and hemorheology," Clinical Hemorheology and Microcirculation, vol. 43, no. 3, pp. 241-249, 2009.

[20] M. Diez-Silva, M. Dao, J. Han, C.-T. Lim, and S. Suresh, "Shape and biomechanical characteristics of human red blood cells in health and disease," MRS Bulletin, vol. 35, no. 5, pp. 382-389, 2010.

[21] R. K. Adosraku, G. T. Choi, V. Constantinou-Kokotos, M. M. Anderson, and W. A. Gibbons, "NMR lipid profiles of cells, tissues, and body fluids: Proton NMR analysis of human erythrocyte lipids," Journal of Lipid Research, vol. 35, no. 11, pp. 1925-1931, 1994.

[22] P. M. A. Bonzoma, A. Nicolaoub, M. Zloha, W. Baldeoa, and W. A. Gibbonsa, "NMR lipid profile of Agaricus bisporus," Phytochemistry, vol. 50, no. 8, pp. 1311-1321, 1999.

[23] K. M. Marzec, D. Perez-Guaita, M. de Veij et al., "Red blood cells polarize green laser light revealing hemoglobin's enhanced non-fundamental Raman modes," ChemPhysChem, vol. 15, no. 18, pp. 3963-3968, 2014.

[24] K. M. Marzec, A. Rygula, B. R. Wood, S. Chlopickia, and M. Baranska, "High-resolution Raman imaging reveals spatial location of heme oxidation sites in single red blood cells of dried smears," Journal of Raman Spectroscopy, vol. 46, no. 1, pp. 76-83, 2015.

[25] J. L. Deng, Q. Wei, M. H. Zhang, Y. Z. Wang, and Y. Q. Li, "Study of the effect of alcohol on single human red blood cells using near-infrared laser tweezers Raman spectroscopy," Journal of Raman Spectroscopy, vol. 36, no. 3, pp. 257-261, 2005.

[26] B. R. Wood, P. Caspers, and G. J. Puppels, "Resonance Raman spectroscopy of red blood cells using near-infrared laser excitation," Analytical and Bioanalytical Chemistry, vol. 387, no. 5, pp. 1691-1703, 2007.

[27] M. K. Marchewka, "2,4,6-Triamino-1,3,5-triazin-1-ium acetate acetic acid solvate monohydrate; infrared and Raman spectra," Bulletin of the Korean Chemical Society, vol. 25, no. 4, pp. 466-470, 2004.

[28] B. R. Wood, B. Tait, and D. McNaughton, "Micro-Raman characterisation of the $\mathrm{R}$ to $\mathrm{T}$ state transition of haemoglobin within a single living erythrocyte," Biochimica et Biophysica Acta, vol. 1539, no. 1, pp. 58-70, 2001.

[29] W. G. Zijlstra and A. Buursma, "Spectrophotometry of hemoglobin: absorption spectra of bovine oxyhemoglobin, deoxyhemoglobin, carboxyhemoglobin, and methemoglobin," Comparative Biochemistry and Physiology, vol. 118B, no. 4, pp. 743-749, 1997.

[30] M. T. Gladwin, J. H. Crawford, and R. P. Patel, “The biochemistry of nitric oxide, nitrite, and hemoglobin: role in blood flow regulation," Free Radical Biology \& Medicine, vol. 36, no. 6, pp. 707-717, 2004.

[31] I. Azarov, K. T. Huang, S. Basu, M. T. Gladwin, N. Hogg, and D. B. Kim-Shapiro, "Nitric oxide scavenging by red blood cells as a function of hematocrit and oxygenation," The Journal of Biological Chemistry, vol. 280, no. 47, pp. 39024-39032, 2005.

[32] D. D. Thomas, X. Liu, S. P. Kantrow, and J. R. Lancaster Jr., "The biological lifetime of nitric oxide: implications for the perivascular dynamics of $\mathrm{NO}$ and $\mathrm{O}_{2}$," PNAS, vol. 98, no. 1, pp. 355-360, 2001.

[33] L. F. De Figueiredo, M. Mathru, D. Solanki, V. W. Macdonald, J. Hess, and G. C. Kramer, "Pulmonary hypertension and systemic vasoconstriction may offset the benefits for acellular hemoglobin blood substitutes," The Journal of Trauma, vol. 42, no. 5, pp. 847-854, 1997.

[34] S. Kim and R. Chang, "Structure, dynamics, and phase behavior of DOPC/DSPC mixture membrane systems: molecular dynamics simulation studies," Bulletin of the Korean Chemical Society, vol. 37, no. 7, pp. 1076-1085, 2016. 
[35] E. J. Szili, S. H. Hong, and R. D. Short, "On the effect of serum on the transport of reactive oxygen species," Biointerphases, vol. 10, no. 2 article 029511, 2015.

[36] S. H. Ki, J. K. Park, C. Sung et al., "Artificial vesicles as an animal cell model for the study of biological application of non-thermal plasma," Journal of Physics D: Applied Physics, vol. 49 , no. 8 article $085401,2016$. 


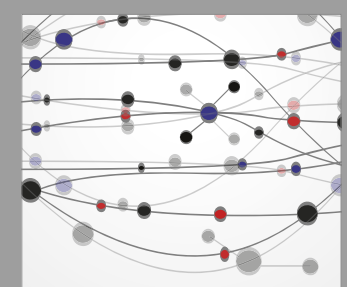

The Scientific World Journal
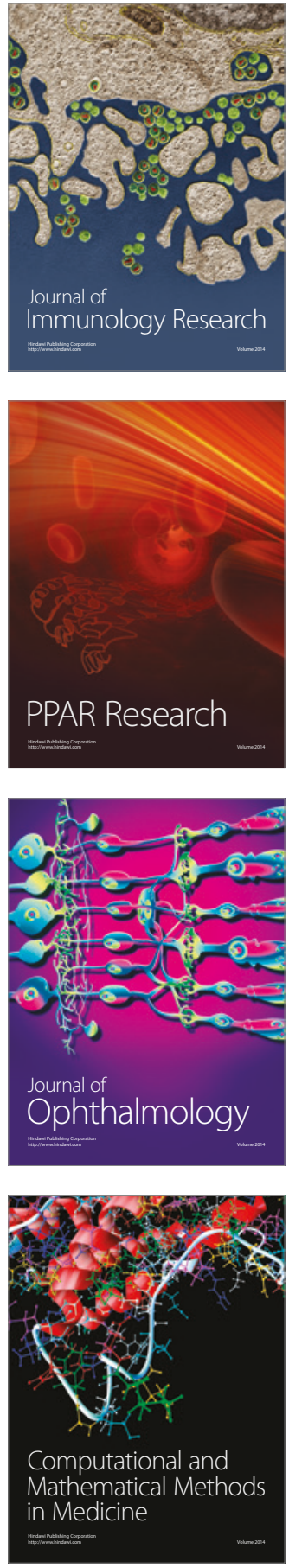

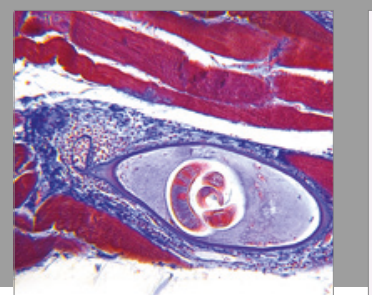

Gastroenterology Research and Practice
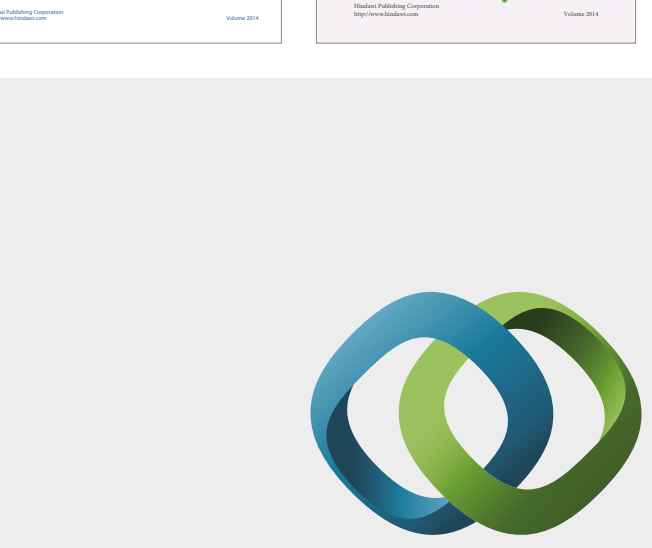

\section{Hindawi}

Submit your manuscripts at

https://www.hindawi.com
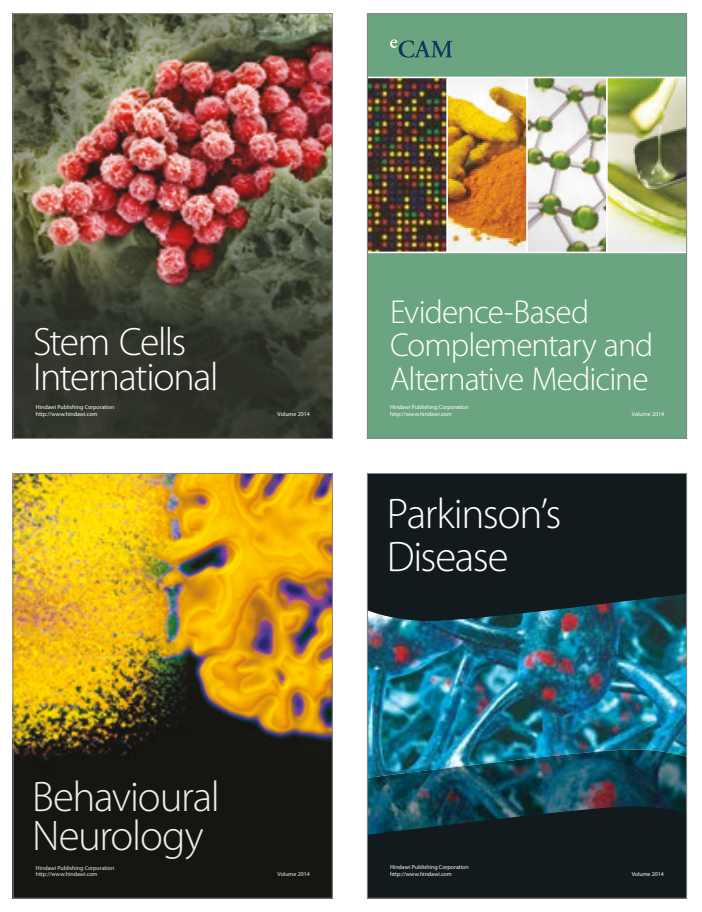
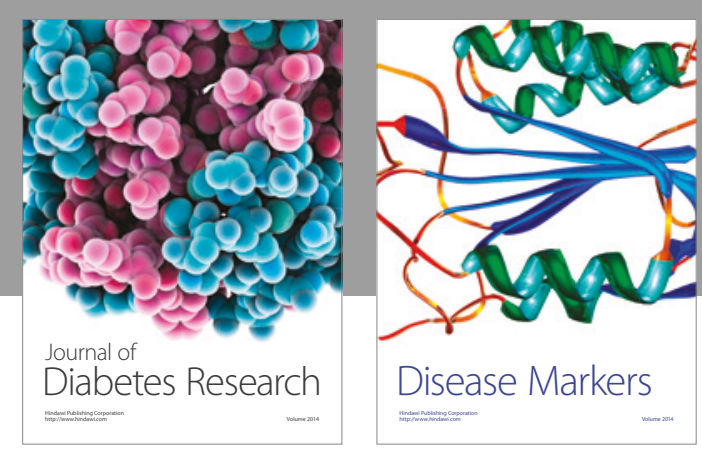

Disease Markers
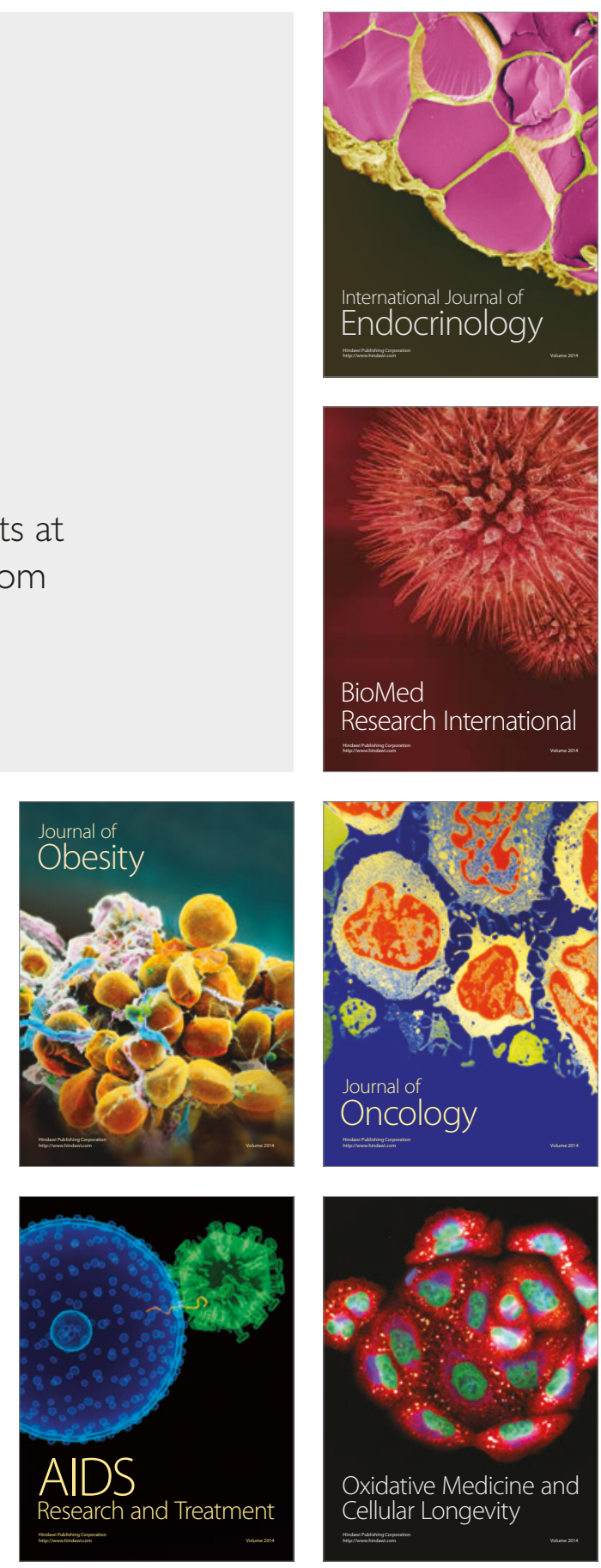